\title{
The Role of Concomitant Mastoidectomy in Improving Outcomes Following Tympanic Membrane Perforation Repair: A Systematic Review
}

\author{
EMAN A. EBRAHIM, M.Sc.; HOSSAM S. EL-SHERIF, M.D.; SHAABAN B. MOHAMMED, M.D. and \\ FATTHE A. ERFAN, M.D.
}

The Department of Otorhinolaryngology, Faculty of Medicine, Tanta University, Tanta, Egypt

\begin{abstract}
Background: The role of mastoidectomy performed with tympanoplasty for tympanic membrane perforations in the absence of cholesteatoma remains controversial. Many otolaryngologists continue to routinely perform mastoidectomy with tympanoplasty, others argue that performing mastoidectomy in these patients is unnecessary, does not improve surgical outcomes, and subjects patients to increased surgical risks.
\end{abstract}

Aim of the Work: To assess the effectiveness and safety of performing routine cortical mastoidectomy in addition to tympanoplasty in treatment of tympanic membrane perforation in cases of chronic suppurative otitis media in the absence of cholesteatoma.

Patients and Methods: Five randomized controlled trials with total of 610 participents were included of any age with chronic suppurative non cholestaetomatous otitis media, divided into two groups: Group A (received Tympanoplasty alone), Group B (Tymanplasty with cortical mastoidectomy).

Five outcomes measured namely (healing rate, hearing rate, tympanometric evaluation, rate if otorrhea, need for subsequent procedure).

Results: Articles reporting results of concomitant mastoidectomy with tympanoplasty were identified. Five articles satisfied our eligibility criteria, there was no significant heterogeneity. Compared to the conventional method tympanoplasty with cortical mastoidectomy was found to have a significantly higher rate of healing (odds ratio of 1.762 with a $95 \%$ CI of -1.115 to 2.787 , no significant difference in postoperative air bone gap (SMD of .056 with $95 \%$ CI of -0.110 to 0.222 ), no significant difference in rate of otorrhea (odds ratio of 1.949 with a $95 \%$ CI of 0.528 to 7.192 , no significant difference in post-operative tympanometry (odds ratio of type A, Astympanometry was 0.777 and a $95 \%$ CI of 0.278 to 2.179 , no significant difference in rate of revision surgery (odds ratio 2.069 and a $95 \%$ CI of 0.178 to 24.075 .

Correspondence to: Dr. Eman A. Ebrahim, The Department of Otolaryngology, Faculty of Medicine, Tanta University
Conclusions: From the result s of our systematic review we advise for the use of tympanoplasty alone for treatment of non cholesteatomatous chronic otitis media.

Key Words: Tympanoplasty or myringoplasty and mastoidectomy or tympa - Nomastoidectomy.

\section{Introduction}

TYMPANIC Membrane (TM) perforations are associated with various pathological ear conditions. Tympanoplasty is a commonly performed surgical procedure to close perforations of the tympanic membrane [1]. The results of tympanic membrane repair, although generally favorable, can vary significantly based on multiple factors including infection, eustachian tube dysfunction, and variations in operative technique the rationale of adding mastoidectomy to tympanoplasty is based on the concept that surgical aereation of the mastoid will improve outcomes by providing a reservoire of air that can buffer pressure changes in the middle ear according to Boyle's law [2] devitalized tissues that can lead to persistent middle ear disease.

The aim of the work is to assess the effectiveness and safety of performing routine cortical mastoidectomy in addition to tympanoplasty in treatment of tympanic membrane perforation in cases of chronic suppurative otitis media in the absence of cholesteatoma.

\section{Patients and Methods}

This study was conducted in ENT Department, Tanta University Hospitals from April to October 2015, randomized controlled trials were included in the study, including patients of any age with tympanic membrane perforation in cases of chronic suppurative otitis media,in absence of cholesteato- 
ma, comparing tympanoplasty with cortical mastoidectomy and tympanoplasty alone. Outcomes measured were: Closure of tympanic membrane perforation, imprtric changeovement of otorrhea, tympanometric changes, adverse events and need for subsequent procedure.

We conducted systematic searches for clinical trials with no study type, language, publication year or publication status restrictions.

We searched the following databases from their inception for published, unpublished and ongoing trials: The Cochrane Ear, Nose and Throat Disorders Group Trials Register, the Cochrane Central Register of Controlled Trials (CENTRAL, PubMed, EMBASE, LILACS, Korea Med, Ind Med, Pak Med iNet, Clinical Trials. gov, ICTRP (International Clinical Trials Registry Platform), Google and other sources.

Search terms included tympanoplasty or myringoplasty and mastoidectomy or tympano-mastoidectomy.

We searched the 'grey literature' such as books, journal articles, conference abstracts and table of contents for relevant studies that fulfill our inclusion criteria.

We scanned the reference lists of identified publications for additional trials and contact trial authors where necessary. In addition, we searched PubMed, TRIP database, NHS Evidence-ENT and Audiology, and Google to retrieve existing systematic reviews relevant to this systematic review.

\section{Data collection and analysis:}

Firsly two reviewer independently assessed all potential studies as identified by the search strategy for eligibility, which were already defined. We obtained full-text articles if the relevant information to enable inclusion/exclusion was not apparent from the title or abstract. Disagreements were settled by discussion with third reviewer. We excluded studies that did not meet the inclusion criteria for this review and stated the reason in the "Charecteristic of excluded studies" table. Then two review authors independently extracted data from the full texts of included studies using a specifically developed extraction form. The data extraction form was piloted.

Previously information will be collected on the following:

Study characteristics (first author, year of publication, study design, number of arms, sample size, duration of follow-up).
Participant characteristics (age, sex, numbers of participants, inclusion and exclusion criteria in the included studies) and possible confounders (previous treatment, co-medication, co-morbidities and other confounders as reported by authors).

Intervention and comparator details. (Sample size for each treatment arm, blinding, type of interventions).

The assessment of risk of bias was performed by two reviewers independently considering the following domains according to the Cochrane risk of bias tool: Sequence generation, allocation concealment, blinding of (participants, personnel, and outcome assessors), incomplete outcome data, selective outcome reporting, and other sources of bias for the RCTs. According to the Cochrane Handbook, these items will be described as having a 'low', 'high', or 'unclear' risk of bias [3]

\section{Measures of treatment effect:}

We analyzed the primary outcome 'Tympanic membrane healing' as a dichotomous outcome 'success of healing'. The treatment effect for dichotomous out-comes (adverse events) was expressed as a Risk Ratio (RR) with $95 \%$ confidence intervals. The treatment effect for each continuous outcome (hearing outcome) was expressed as a Mean Difference (MD) with 95\% Confidence Interval (CI). Where continuous outcomes were measured using different scales, the treatment effect was expressed as a Standardized Mean Difference (SMD) with 95\% CI.

We assessed the impact of heterogeneity on any meta-analyses we performed using the I2 statistic. In the absence of significant heterogeneity, we used a fixed-effect model.

We planned to minimize the impact of reporting bias in our systematic review by ensuring a comprehensive search for eligible studies including three trial registries. A funnel plot and appropriate statistical tests for small study effects will be performed if $>10$ studies are available [4]

\section{Data synthesis:}

Estimation of treatment effects was based on a fixed effect model, when we are faced with substantial heterogeneity, a random effects model will be calculated as well as sensitivity analysis. We calculated pooled RRs and 95\% CIs across comparable studies. When considerable heterogeneity (I2 >80\%) was found between comparable studies, pooled estimates was not be provided. Instead, a descriptive synthesis of findings was performed. 
Subgroup analysis and investigation of heterogeneity.

Sensitivity analysis:

Summary of findings table:

A grade of quality of evidence for each outcome GRADE approach was used Schunemann, et al.. [5].

\section{Results}

The initial search yielded 5806 articles, through screeningof titles and abstracts and removing duplicates 5784 were excluded based on initial criteria the remaining 22 articles were reviewed then screened in detail by examining the full text and 17 more articles were excluded this left 5 articles meeting the eligibility criteria.

Healing rate: Pooling of the estimates using a fixed effects model showed an odds ratio of 1.762 with a $95 \%$ CI of -1.115 to 2.784 which was statistically significant $(\mathrm{z}, 2.427 ; p$-value, 0.015$)$ favoring tympanoplasty with cortical mastoidectomy. Estimated from the 5 studies.

BHAT et al. [6], Ramakrishnan et al. [7], Abdel Tawab et al. [8], Krishnan et al. [9], Albu et al. [10].

Rate of otorrhea: Pooling of the estimates using a fixed effects model showed an odds ratio of 1.949 with a $95 \%$ CI of 0.528 to 7.192 which was not statistically significant $(\mathrm{z}, 1.002 ; p$-value, 0.316$)$ estimated from 2 studies (Abd El-Tawab et al., Bhat et al.).

Audiometric changes: Pooling of the estimates using a fixed effects model showed a Standardized Mean Difference (SMD) of 0.056 with a $95 \%$ CI of -0.110 to 0.222 which was not statistically significant $(t, 0.660 ; p$-value, 0.509$)$ estimated from 5 studies.

Tympanometric changes: The odds ratio for type A/As tympanometry as estimated from the single study reporting on this outcome (Bhat et al., 2009).

The odds ratio for type A/As tympanometry was 0.777 (95\% CI, 0.278 to 2.174) which was not statistically significant $(\mathrm{z},-0.480 ; p$-value, $0.631)$.

Need for subsequent procedure: Odds ratio for revision surgery as estimated from the single study reporting on this outcome (Ramakrishnan et al., 2011 [10] was 2.069 (95\% CI, 0.178 to 24.075 ) which was not statistically significant $(\mathrm{z}, 0.581$; $p$-value, 0.561).

Overall completeness and applicability of evidence: We included 5 randomized controlled trials, all of them directly relevant to the objectives of our review. Using the GRADE approach our review provided a low-powered evidence on the domain of healing rate, audiological assessment and adverse events and need for subsequent procedure, highpowered evidence on the domain of rate of otorrhea, and moderate-powered on the domain of tympanometric changes.

The five studies had different grades of risk of bias concerning the different domains of assessment of bias but with overall judgment of 'Unclear' risk of bias in the five trials. However, there was no noticeable heterogeneity detected in cases where we could perform pooling of data and Metaanalysis. Two of the included studies were carried out in tertiary referral centre and the remeaning studies were carried out in Specialized Department of a Central Hospital.

Potential biases in the review process: We attempted to identify every relevant trial using a rigorous search strategy. Two authors independently applied the same search methodology and resolved disagreement by consensus. Publication Bias is unlikely to be considered a potential threat to the validity of results of this review.

Table (1): Results-intervention-outcomes.

\begin{tabular}{|c|c|c|c|c|c|c|c|c|c|c|}
\hline \multirow[b]{2}{*}{ Outcome/study } & \multicolumn{2}{|c|}{$\begin{array}{l}\text { Kv Bhat } \\
\text { et al., }\end{array}$} & \multicolumn{2}{|c|}{$\begin{array}{l}\text { Ramakrishnan } \\
\text { et al., }\end{array}$} & \multicolumn{2}{|c|}{$\begin{array}{l}\text { Abd Elwahab } \\
\text { et al., }\end{array}$} & \multicolumn{2}{|c|}{$\begin{array}{l}\text { Krishnan } \\
\text { et al., }\end{array}$} & \multicolumn{2}{|c|}{$\begin{array}{l}\text { Albu } \\
\text { et al., }\end{array}$} \\
\hline & $\begin{array}{c}\text { Study } \\
\text { group } \\
\text { no }(\mathrm{A}) \\
31\end{array}$ & $\begin{array}{c}\text { Control } \\
\text { group } \\
\text { no (B) } \\
29\end{array}$ & $\begin{array}{l}\text { A } \\
\text { no } \\
31\end{array}$ & $\begin{array}{c}\text { B } \\
\text { no } \\
31\end{array}$ & $\begin{array}{l}\text { A } \\
20\end{array}$ & $\begin{array}{c}\text { B } \\
20\end{array}$ & $\begin{array}{l}\text { A } \\
76\end{array}$ & $\begin{array}{l}\text { B } \\
44\end{array}$ & $\begin{array}{c}\text { A } \\
140\end{array}$ & $\begin{array}{c}\text { B } \\
142\end{array}$ \\
\hline - Hearling rate & $80.64 \%$ & $79.31 \%$ & $93.5 \%$ & $96.77 \%$ & $80 \%$ & $70 \%$ & $94.7 \%$ & $81 \%$ & $82.85 \%$ & $76 \%$ \\
\hline \multirow[t]{2}{*}{ - Audiological evaluation } & $7.29 \pm$ & $12.42 \pm$ & $12.55 \pm$ & $12.71 \pm$ & $20 \pm$ & $18.3 \pm$ & $34.84 \pm$ & $35.59 \pm$ & $12.4 \pm$ & $11.2 \pm$ \\
\hline & 16.34 & 15.49 & 12.98 & 11.54 & 8.3 & 10 & 14.51 & 12.5 & 6.1 & 6.8 \\
\hline - Rate of otorrhea & $6.89 \%$ & $6.89 \%$ & - & - & $10 \%$ & $25 \%$ & $0 \%$ & $0 \%$ & - & - \\
\hline - Tympanometric evaluation & $40 \%$ & $44 \%$ & - & - & - & - & - & - & - & - \\
\hline - Adverse events and need for subsequent procedure & $3.22 \%$ & $3.44 \%$ & - & - & - & - & - & - & - & - \\
\hline
\end{tabular}


Table (2): Summary of included studies.

\begin{tabular}{|c|c|c|c|c|c|}
\hline Author & Type of Article & $\begin{array}{l}\text { Number of } \\
\text { patients total } \\
\text { (tympanoplasty } \\
\text { alone) }\end{array}$ & Comparator & Mean age & Outcomes measured \\
\hline Bhat et al. & $\begin{array}{l}\text { Randomized } \\
\text { controlled trial }\end{array}$ & $68(33)$ & 35 & $12-52$ & $\begin{array}{l}\text { Graft success } \\
\text { Improvement of otorrhea } \\
\text { Improvement of hearing status } \\
\text { Tympanmetric evaluation } \\
\text { Adverse events and need for subsequent surgery }\end{array}$ \\
\hline Ramakrishan et al. & $\begin{array}{l}\text { Randomized } \\
\text { controlled trial }\end{array}$ & $62(31)$ & 31 & $23.55 \pm 10.55$ & $\begin{array}{l}\text { Graft success } \\
\text { Improvement of hearing status } \\
\text { Need for subsequent surgery }\end{array}$ \\
\hline Abd El-Wahab & $\begin{array}{l}\text { Randomized } \\
\text { controlled trial }\end{array}$ & $40(20)$ & 20 & $12-60$ & $\begin{array}{l}\text { Graft success } \\
\text { Improvement of otorrhea } \\
\text { Improvement of hearing status }\end{array}$ \\
\hline Krishnan et al. & $\begin{array}{l}\text { Randomized } \\
\text { controlled trial }\end{array}$ & $120(44)$ & 76 & Not mentioned & $\begin{array}{l}\text { Graft success } \\
\text { Improvement of otorrhea } \\
\text { Improvement of hearing status }\end{array}$ \\
\hline Albu et al. & $\begin{array}{l}\text { Randomized } \\
\text { controlled trial }\end{array}$ & $320(160)$ & 160 & $15-39$ & $\begin{array}{l}\text { Graft success } \\
\text { Improvement of hearing status }\end{array}$ \\
\hline
\end{tabular}

Table (3): Summary of findings.

Tympanoplasty with cortical mastoidectomy compared to tympanoplasty alone for closure of tympanic membrane perforations

Patient or population: Closure of tympanic membrane perforations.

Setting: University affiliated hospital.

Intervention: Tympanoplasty with cortical mastoidectomy.

Comparison: Tympanoplasty alone.

\begin{tabular}{|c|c|c|c|c|c|}
\hline & \multicolumn{2}{|c|}{ Anticipated absolute effects*(95\% CI) } & & & \\
\hline & $\begin{array}{l}\text { Risk with } \\
\text { tympanoplasty } \\
\text { alone }\end{array}$ & $\begin{array}{c}\text { Risk with } \\
\text { tympanoplasty with } \\
\text { cortical mastoidectomy }\end{array}$ & & & \\
\hline $\begin{array}{l}\text { Rate of healing (healing) } \\
\text { follow-up: Mean } 6 \text { months }\end{array}$ & 79 per 100 & $\begin{array}{l}87 \text { per } 100 \\
(81 \text { to } 91)\end{array}$ & $\begin{array}{l}\text { OR } 1.762 \\
\text { (1.115 to } 2.784)\end{array}$ & $\begin{array}{l}564 \\
(5 \mathrm{RCTs})\end{array}$ & $\begin{array}{l}\oplus \oplus \bigcirc \mathrm{O} \\
\text { Low } 1,2\end{array}$ \\
\hline $\begin{array}{l}\text { Rate of otorrhoea (otorrhoea) } \\
\text { follow-up: Mean } 6 \text { months }\end{array}$ & 86 per 100 & $\begin{array}{l}92 \text { per } 100 \\
(76 \text { to } 98)\end{array}$ & $\begin{array}{l}\text { OR } 1.949 \\
(0.528 \text { to } 7.192)\end{array}$ & $\begin{array}{l}100 \\
(2 \mathrm{RCTs})\end{array}$ & $\begin{array}{l}\oplus \oplus \oplus \oplus \\
\text { High }\end{array}$ \\
\hline $\begin{array}{l}\text { Audiological evaluation (hearing) } \\
\text { assessed with: PTA } \\
\text { follow-up: Mean } 6 \text { months }\end{array}$ & - & - & - & $\begin{array}{l}564 \\
(5 \text { RCTs })\end{array}$ & $\begin{array}{l}\oplus \oplus \bigcirc \bigcirc \\
\text { Low } 1,2\end{array}$ \\
\hline $\begin{array}{l}\text { Tympanometric changes (tympanometry) } \\
\text { assessed with: Tympanometry } \\
\text { follow-up: Mean } 6 \text { months }\end{array}$ & 45 per 100 & $\begin{array}{l}39 \text { per } 100 \\
(18 \text { to } 64)\end{array}$ & $\begin{array}{l}\text { OR } 0.777 \\
(0.278 \text { to } 2.174)\end{array}$ & $\begin{array}{l}60 \\
(1 \mathrm{RCT})\end{array}$ & $\begin{array}{l}\oplus \oplus \bigcirc \bigcirc \\
\text { Moderate } 3\end{array}$ \\
\hline $\begin{array}{l}\text { Need for subsequent procedures (rate of revision surgery) } \\
\text { follow-up: Mean } 6 \text { months }\end{array}$ & 3 per 100 & $\begin{array}{l}6 \text { per } 100 \\
(1 \text { to } 45)\end{array}$ & $\begin{array}{l}\text { OR } 2.069 \\
(0.178 \text { to } 24.075)\end{array}$ & $\begin{array}{l}62 \\
(1 \mathrm{RCT})\end{array}$ & $\begin{array}{l}\oplus \oplus \bigcirc \bigcirc \\
\text { Low } 3,4\end{array}$ \\
\hline
\end{tabular}

*: The risk in the intervention group (and its $95 \%$ confidence interval) is based on the assumed risk in the comparison group and the relative effect of the intervention (and its 95\% CI).

CI : Confidence Interval.

OR : Odds Ratio.

SMD: Standardised Mean Difference.

GRADE Working Group grades of evidence.

High quality: We are very confident that the true effect lies close to that of the estimate of the effect.

Moderate quality: We are moderately confident in the effect estimate: The true effect is likely to be close to the estimate of the effect, but there is a possibility that it is substantially different.

Low quality: Our confidence in the effect estimate is limited: The true effect may be substantially different from the estimate of the effect.

Very low quality: We have very little confidence in the effect estimate: The true effect is likely to be substantially different from the estimate of effect. 


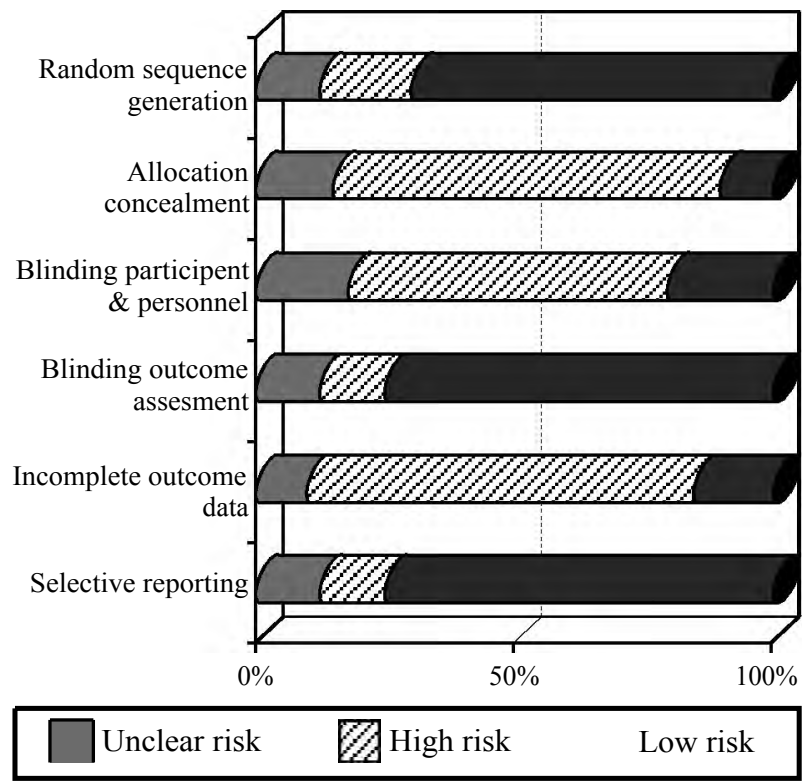

Fig. (1): Risk of bias assessment in Albu et al.

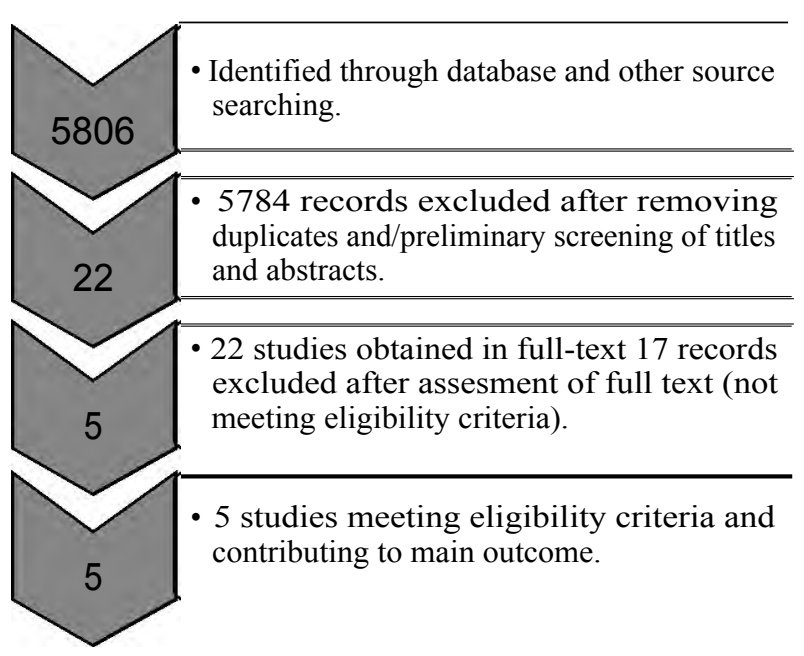

Fig. (2): Study flow diagram (Prisma).

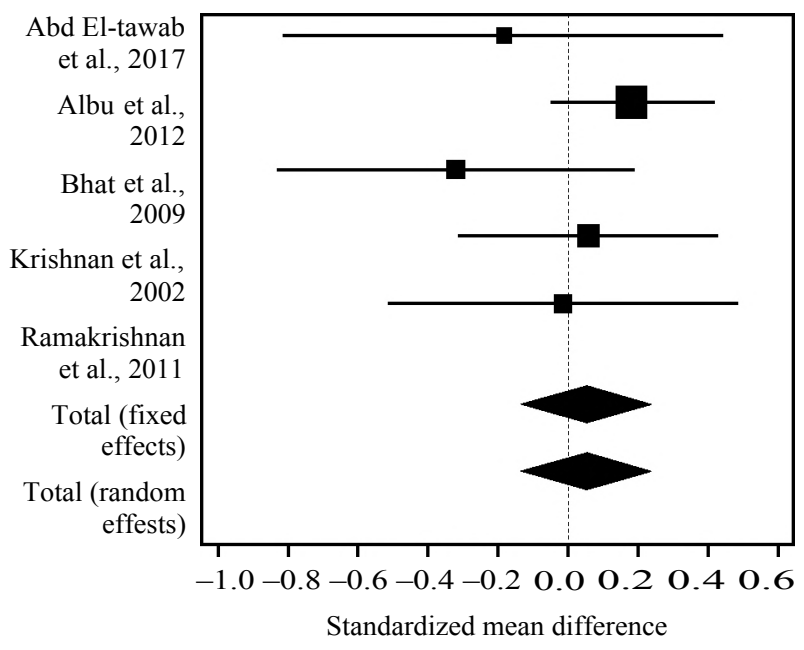

Fig. (3): Funnel plot-audiological evaluation.

\section{Discussion}

\section{dence:}

We included 5 randomized controlled trials, all of them directly relevant to the objectives of our review. Using the GRADE approach our review provided a low-powered evidence on the domain of healing rate, audiological assessment and adverse events and need for subsequent procedure, high powered evidence on the domain of rate of otorrhea, and moderate-powered on the domain of tympanometric changes.

Quality of the evidence: The five studies had different grades of risk of bias concerning the different domains of assessment of bias but with overall judgment of 'Unclear' risk of bias in the five trials. However, there was no noticeable heterogeneity detected in cases where we could perform pooling of data and meta-analysis. Two of the included studies were carried out in tertiary referral centre and the remeaning studies were carried out in specialized department of a central hospital.

Potential biases in the review process: We attempted to identify every relevant trial using a rigorous search strategy. Two authors independently applied the same search methodology and resolved disagreement by consensus. Publication Bias is unlikely to be considered a potential threat to the validity of results of this review.

\section{Conclusion:}

From the results of this systematic review we concluded that tympanoplasty alone is effective in treatment of non cholestaetomatus chronic suppurative otitis media.

Limitations: The generalizability of this review is restricted by a number of factors: The included trials were carried out in university-affiliated and central hospitals. It is conceivable that patients recruited from such secondary and tertiary care levels are likely to suffer from a more severe form of the disease compared to those attending their general practitioner. Thus the extent to which the results of this review are generalizable to primary care is at least a bit diminished.

The techniques, instruments and devices employed in the included trials are reasonably only available at a higher level of care health facilities.

\section{Acknowledgments:}

This research was carried out without funding. 


\section{Conflicts of interest:}

No conflicts of interest declared.

\section{References}

1- WEHRS R.E.: Aeration of the middle ear and mastoid in tympanoplasty. Laryngoscope, 91: 1463-8, 1981.

2- RUHL C.M. and PENSAK M.L.: Role of aerating mastoidectomy in non cholesteatomatous chronic otitis media. Laryngoscope, 109: 1924-7, 1999.

3- HIGGINS J.P.T. and GREEN S.: Cochrane Handbook for Systematic Reviews of Interventions Version 5.1 The Cochrane Collaboration, 2011.

4- STERNE J.A., SUTTON A.J., IOANNIDIS J.P., et al.: Recommendations for examining and interpreting funnel plot asymmetry in meta-analyses of randomised controlled trials. British Medical Journal, 343: d4002, 2011.

5- SCHUNEMANN H.J., OXMAN A.D., VIST G.E., et al.: Interpreting results and drawing conclusions. In: Higgins JPT, Green S, Cochrane Handbook for Systematic Reviews of Interventions Version 5.1.0.
6- K.V. BHAT, K. NASEERUDDIN, U.S. NAGALOTIMATH, et al.: Cortical mastoidectomy in quiescent, tubotympanic, chronic otitis media: Is it routinely necessary? The Journal of Laryngology \& Otology, 123: 38390, 2009.

7- ATHIRA RAMAKRISHNAN, NARESH K. PANDA, et al.: Cortical mastoidectomy in surgery of tubotympanicdisease. Are we overdoing it? The Surgeon, 9: 22-6, 2011.

8- HAZEM MOHAMMED ABDEL TAWAB, FADI MAHMOUD GHARIB, TAREQ M. ALGARF, et al.: Myringoplasty with and without Cortical Mastoidectomy in Treatmentof Non-cholesteatomatous Chronic Otitis Media: A Comparative Study. Clinical Medicine Insights: Ear, Nose and Throat, 7: 19-23, 2014.

9- ANITA KRISHNAN, E.K. REDDY, C. CHANDRAKIRAN, et al:: Tympanoplasty With And Without Corticalmastoidectomy-A Comparative Study. Indian Journal of Otolaryngology and Head and Neck, 54: 3, 2002.

10- SILVIU ALBU, FRANCO TRABALZINI, and MAURIZIO AMADORI: Usefulness of Cortical Mastoidectomy in Myringoplasty. Otology \& Neurotology, 33: 604-5, 2010.

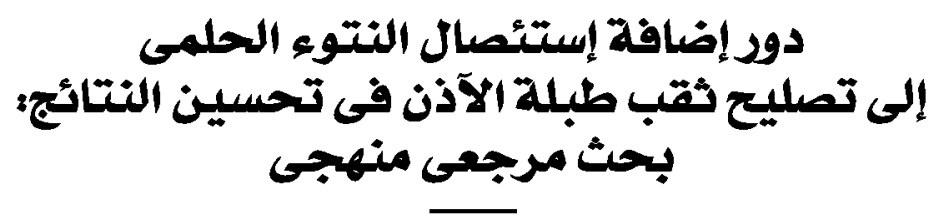

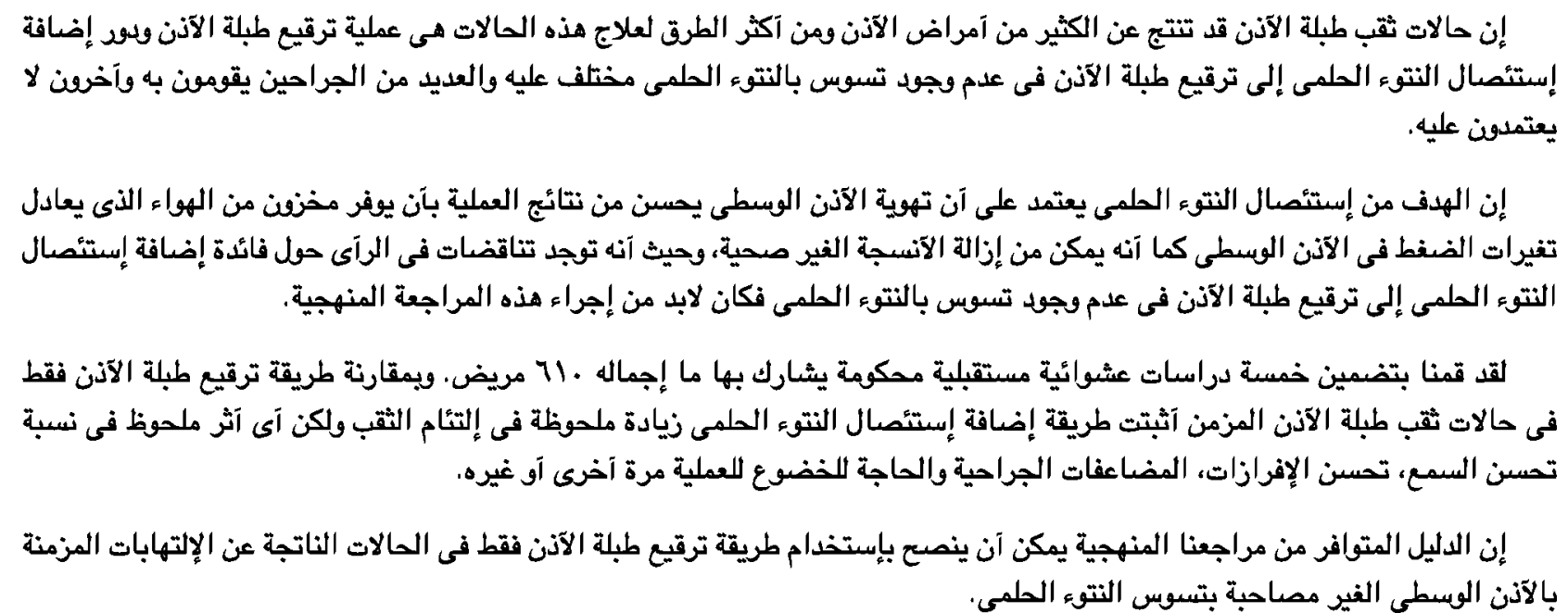

